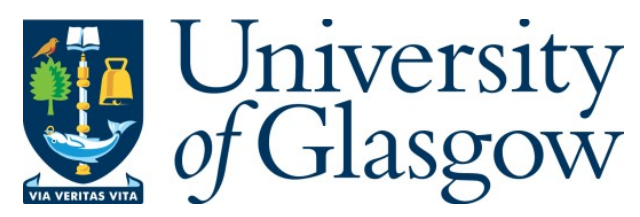

Carter, J. A. (2013) A problem for Pritchard's anti-luck virtue epistemology. Erkenntnis, 78(2), pp. 253-275.

There may be differences between this version and the published version. You are advised to consult the publisher's version if you wish to cite from it.

http://eprints.gla.ac.uk/134859/

Deposited on: 23 January 2017

Enlighten - Research publications by members of the University of Glasgow http://eprints.gla.ac.uk 


\title{
A PROBlem FOR PRITCHARD'S ANTI-LUCK VIRTUE EPISTEMOLOGY
}

\author{
J. Adam Carter (forthcoming in Erkenntnis)
}

\begin{abstract}
Duncan Pritchard has, in the years following his (2005) defence of a safety-based account of knowledge in Epistemic Luck, abjured his (2005) view that knowledge can be analysed exclusively in terms of a modal safety condition. He has since $(2007 ; 2009 ; 2010)$ opted for an account according to which two distinct conditions function with equal importance and weight within an analysis of knowledge: an anti-luck condition (safety) and an ability condition-the latter being a condition aimed at preserving what Pritchard now takes to be a fundamental insight about knowledge: that it arises from cognitive ability (Greco (2010); Sosa $(2007$; 2009). Pritchard calls his new view anti-luck virtue epistemology (ALVE). A key premise in Pritchard's argument for ALVE is what I call the independence thesis; the thesis that satisfying neither the anti-luck condition nor the ability condition entails that the other is satisfied. Pritchard's argument for the independence thesis relies crucially upon the case he makes for thinking that cognitive achievements are compatible with knowledge-undermining environmental luck-that is, the sort of luck widely thought to undermine knowledge in standard barn facade cases. In the first part of this paper, I outline the key steps in Pritchard's argument for anti-luck virtue epistemology and highlight how it is that the compatibility of cognitive achievement and knowledgeundermining environmental luck is indispensible to the argument's success. The second part of this paper aims to show that this compatibility premise crucial to Pritchard's argument is incorrect.
\end{abstract}

\section{Part I \\ Motivating Anti-Luck Virtue Epistemology}

Two insights key to Pritchard's (2007; 2008; 2009; 2010; 2011) new theory of knowledge-anti-luck virtue epistemology (ALVE)-are that (put simply) (i) knowlege excludes luck; and (ii) knowledge arises from ability. These insights are crucial to motivating his ALVE account-which will be the critical focus of this paper-and so I think it will be useful to begin by making precise what each 
respective insight is supposed to capture about knowledge and how the two insights are, in a clear sense, related to each other.

\section{The Anti-Luck Intuition}

One might initially balk at the claim that knowledge excludes luck on the grounds that it's implausibly strong. Consider after all that, prima facie, one's knowing some proposition and yet luckily acquiring the truth don't always seem incompatible. It is natural, after all, to remark that it's just a matter of luck that some knowers have the particular truths they do rather than, say, other truths, or no truths at all. Someone (say, James) who narrowly escapes a car wreck might be thought lucky to be in possession of any of the truths he presently has-after all, James is quite lucky to be in possession of a working brain, and therefore, to be in possession any thoughts, truth-apt or otherwise. In this sense, James has knowledge even though his having possession of the truths he does seems to be a matter of luck. Likewise, we might remark that some student-say, Emma-would strike us as lucky to know some interesting, obscure fact $N$ about Napoleon she picked up from her revered European History professor when, had it not been for a fortunate glitch in the registrar's computer, she would have been assigned instead to a less knowledgable European History professor who would not have communicated $N$.

In these cases, the point that knowledge does seem to depend on luck counts neither for nor against the more philosophically interesting idea epistemologists have in mind when endorsing what they take to be a platitude about knowledge as it stands in relation to luck. The relevant platitude here-call it the anti-luck platitude-is one that epistemologists intend to capture when they say that (for example) knowledge does not arise through luck or isn't held luckily or is incompatible with luck or doesn't depend on luck, etc. The motivation for such remarks is (more or less) the same one we ourselves might have when, for example, we are inclined to firmly deny that a confident gambler who correctly bets that a fair coin will land heads counts as having known that it would do so. Given that the coin is fair, it doesn't matter whether the gambler is on a hot streak or whether he claims a subjective credence of 1 that the coin will land heads. We know that whatever method the gambler employs will always leave him just as likely wrong as right on a given coin. We deny then that the gambler can ever know he will be right on a given bet because we have (at least implicitly) in mind a general idea about how knowledge stands related to luck: put roughly, the idea is that for some agent $S$ to count as knowing a proposition $p$, then given how it is that $S$ came to form her belief that $p$, it can't just be (as it was for the naïve gambler) a matter of luck that the target belief $(p)$ is true.

Though this is the idea at the very crux of the platitude that knowledge excludes luck, it is not as stated sufficiently precise. After all, what exactly do we mean when we say something is not a matter of luck? Though there 
is some disagreement on this point ${ }^{1}$, a standard way of thinking about lucky events is to hold them to be ones that could easily have not occurred. This idea lends itself naturally to a modal representation. Following Pritchard (2005) let's say that an event $E$ is lucky just in case it is an event that occurs in the actual world but which does not occur in a wide class of the nearest possible worlds where the relevant initial conditions for that event are the same as they are in the actual world (Pritchard, 2005: 128). We can think of one's coming to have a true belief as a type of event, and so $S^{\prime}$ s believing $p$ truly is lucky when $S$ believes falsely (on the matter of whether $p$ ) in a wide class of nearby possible worlds where the relevant initial conditions (that led to $S^{\prime}$ s belief about $p$ ) are the same as they are in the actual world. If $S^{\prime}$ s true belief that $p$ is 'lucky', then, (given how $S$ formed her belief) it could easily have been false, given the relevant initial conditions for $S^{\prime}$ s having formed it. We can capture then the core idea expressed in modal terms more plainly: the various expressions (i.e. knowledge cannot depend on luck, knowledge excludes luck, etc.) of the antiluck platitude are all gesturing to the same, rather straightforward idea: one fails to know if, given how she forms her belief, she could easily have been wrong.

Putting this all together, we can see then that there is one sense in which we are right to say that knowledge can depend on luck, and another sense in which it is intuitive to insist that it can't. For ease of reference, let's call the type of epistemically benign luck upon which we say knowledge can depend situational luck: S's belief that $p$ is 'situationally lucky' when (as was the case for James and Emma) it is a matter of luck that the agent has the true belief $(p)$ that he or she does. In these cases, the idea is not that it's a matter of luck that $S$ has the true belief $(p)$ she does given how she formed her belief (about whether or not $p$ ). The idea is that, regardless of how she formed her belief, it's a matter of luck that $S$ came to have that true belief that she does. Expressed more formally:

Situational Luck: $S^{\prime}$ s believing $p$ truly is situationally lucky iff $S$ does not believe $p$ truly in a wide class of nearby possible worlds.

Since we're not-in the context of assessing situational luck-holding fixed the relevant initial conditions for how $S$ formed her belief (about whether or not $p$ ) in the actual world, some nearby worlds might be worlds where $S$ fails to believe $p$ truly not because $S$ formed a belief about $p$ and was wrong, but because $S$ never formed a belief about $p$ at all. After all, taking the case of Emma and the computer glitch that resulted in her taking European history, Emma's true belief $N$ about Napoleon is situationally lucky not because she could have easily believed something false about Napoleon ${ }^{2}$ - but because she could easily have been in a different class, believing things about American History instead.

That said, and following Pritchard (2005), I'll be referring to the sort of luck epistemologists have in mind when claiming that knowledge cannot depend

\footnotetext{
${ }^{1} \mathrm{~A}$ case for rejection of the modal account of luck is found Lackey (2007). For an alternative 'lack of control' account of luck, see Riggs (2007; 2009), Zimmerman (2002), Greco (2006).

${ }^{2}$ Let's suppose she was listening attentively and had no evidence that would defeat the professor's testimony.
} 
on luck as veritic luck.

Veritic luck: $S^{\prime}$ s belief that $p$ is veritically lucky when it is a mater of luck that the agent's belief is true.

Having already unpacked the expression 'is a matter of luck', we may express veritic luck - the sort of luck Pritchard claims to be knowledge underminingas follows:

Veritic luck* (Pritchard): S's true belief is veritically lucky iff there is a wide class of possible worlds in which $S$ continues to believe the target proposition, and the relevant initial conditions for the formation of that belief are the same as in the actual world, and yet the belief is false. (Pritchard 2007: 3)

A helpful view to take to the distinction between situational luck and veritic luck is a grammatical one. Consider the structure of the relevant "that clauses" which follow "It is a matter of luck". In the case of situational luck, it is a matter of luck that S has some true belief $p$. The subject of the "that" clause is the agent, and what is a matter of luck is that the subject "has" (an action verb) a true belief. In the case of veritic luck, it is a matter of luck that my belief is true. The subject of the "that" clause is my belief, and what is a matter of luck is that the belief "is" (a linking verb) true. We might say then that the "believing truly" success that, when lucky, is compatible with knowledge is agent-focused, and the "believing truly" success that, when lucky, is not compatible with knowledge is belief-focused. The distinction between situational luck and veritic luck, and their agent-focused and belief-focused complements is an important one, and one that will play a key role in some of the arguments we'll be considering later.

\section{The Ability Intuition}

Bearing in mind then that veritic luck is the sort of luck that matters for knowledge, let's return to a separate but equally apt observation about knowledge: that knowledge arises through ability ${ }^{3}$. This intuition is intuitive in its own right, but moreover, it gains some additional plausibility the more we consider the observation in the previous section that knowledge is incompatible with (veritic) luck. Why might this be?

Consider an example that I think shows how this initial idea can be motivated. Suppose two friends, Stoo and Steph, set out to predict whether it will rain a week from today. Stoo reasons through difficult meterological data and carefully assimilates the results of the data with the opinions of various experts whose testimony he has weighed carefully. "It will rain," says Stoo. Steff, on the other hand, decides to shake her snow globe and look for her answer in the patterns left by the shaken snow. "It will rain," Steff concludes. They are both

\footnotetext{
${ }^{3}$ For some defences of this idea, see, e.g., Greco 2006; 2010, Sosa 2007; 2009, Pritchard 2009, 2010.
} 
correct. ${ }^{4}$ Although both have acquired true beliefs on the matter, it is clearly just a matter of luck that, given how Steff formed her belief, it is true ${ }^{5}$. Regardless of the fact that Steff's epistemic situation here seems impoverished for a variety of reasons (i.e. for instance, Steff lacks epistemic justification for her belief, construed either internalistically or externalistically), the fact that her belief could easily have been false is itself enough to disqualify her as a knower.

That said, an obvious reason why, given how Steff formed her belief, it could have easily been false, is that Steff's belief was not formed with any sort of skill. It was not a belief she acquired on the basis of exercising anything that resembles a cognitive ability we could properly attribute to her. Following Greco (2010) and Sosa here $(2007 ; 2009)$, a plausible way to think about cognitive abilities is as intellectual competences (e.g. belief forming processes, methods, intellectual character traits, etc.) the manifestation or exercise of which reliably brings about true beliefs and the avoidance of error. It's evident that the method employed by Steff, though employed here en route to her gaining a true belief, is clearly not a truth-conducive one-the consultation of snow-globe patterns does not reliably indicate anything about the weather.

Plausibly, Steff's true belief that it will rain would be worthy of knowledge only if her getting it right did not depend on the good fortune that the generally unreliable method she employed generated a true belief on this occasion. Rather, if we're to to rightly credit Steff with knowing that it would rain, she would have to have formed the belief that it would rain through her own intellectual abilities ${ }^{6}$. We can see how it is then that from the idea that knowledge and veritic epistemic luck are incompatible we are lead quite naturally to the idea that knowledge must arise through some relevant sort of cognitive ability or skill. Greco and Pritchard have called this idea-that knowledge arises from ability-the ability intuition.

\section{Two ex ante constraints on an analysis of knowl- edge}

An endorsement of the ability intuition carries with it at the same time a commitment to an ex ante constraint on an analysis of knowledge. Put simply, the constraint binds us to a necessary condition on knowledge:

\section{Ability (constraint) on knowledge (AC): $S$ knows that $p$ only if $S^{\prime}$ s}

\footnotetext{
${ }^{4}$ It won't matter for the present point whether we count Stoo as positively knowing, so we can set his situation aside.

${ }^{5}$ And moreover, we would be well within our rights to present our observation about the luckiness of Steff's having believed truly as itself a salient and entirely sufficient explanation if called upon to defend why she lacks knowledge in this case. Granted, other considerations could play a part in such an explanation, and that's just fine.

${ }^{6}$ Thanks to an anonymous referee for suggesting this presentation of the point, as well as for pointing out that the idea that knowledge arises from ability gains traction from, as Greco has suggested, the idea that it helps us make sense of the way knowledge attributions are suggestive of credit attributions. For more on this point, see Greco (2003).
} 
getting to the truth about whether or not $p$ results from the exercise of $S$ 's cognitive ability (or abilities).

Now as a point of obviousness, the approach to analysing knowledge that is prima facie best suited to accommodating the ability constraint is the virtuetheoretic approach, examples of which include the much-discussed proposals defended by the three towering figures in virtue epistemology: Sosa (2007; 2009), Greco $(2006 ; 2010)$ and Zagzebski (1996). Although these leading writers disagree about (among other things) how the connection knowledge requires between the acquisition of truth and the exercise of intellectual virtue should be understood, they are in solid agreement that one fails to know unless one satisfies the ability constraint (AC). While I've gestured toward the idea that considerations about how knowledge is incompatible with luck count (quite a bit) in favour of thinking that knowledge must come through ability, the condition on knowledge motivated by our intuition about knowledge and ability is distinct and stands as a separate condition on knowledge than that which is motivated by our intuition that knowledge excludes luck. Indeed, the endorsement of the platitude that knowledge excludes (veritic) luck carries with it its own ex ante constraint on an analysis of knowledge-a constraint that binds knowledge with a separate necessary condition. Call this the anti-luck constraint (ALC).

Anti-luck constraint (ALC): $S$ knows that $p$ only if $S^{\prime}$ s getting to the truth about whether or not $p$ is not veritically lucky.

Given that we can think of AC and ALC as distinct constraints (and ipso facto distinct necessary conditions) on an analysis of knowledge, the natural move will be to consider what sort of theory would have the theoretical ammunition needed to ensure that both conditions are met. For a first pass, we might consider the prospects of a flat-footed modal account of knowledge-one that would be squarely suited to satisfying ALC. Here a standard safety theory (Sosa 1991, Pritchard 2005) would be the natural choice; take Pritchard's earlier (op. cit) view, which he no longer endorses, as a fitting example of such a view:

Safety: S's belief is safe iff in most near-by possible worlds in which $S$ continues to form her belief about the target proposition in the same way as the actual world, her belief continues to be true.

Knowledge (Safety): $S$ knows that $p$ if, and only if, $S$ 's belief that $p$ is safe. ${ }^{7}$

\footnotetext{
${ }^{7}$ This would be the commitment of a typical, flatfooted safety-account of knowledge, though it should be pointed out that Pritchard (2005) took himself to be arguing for safety only as a strong necessary condition on knowledge. Further, it should be noted that in recent papers, Pritchard (2007) has slightly modified his original account of safety in order to accomodate what he takes to be, for his original formulation, a tension between Sosa's (2000) garbage-chute style cases and lottery cases. His newer formulation claims: $\left(\mathrm{SP}^{*}\right) \mathrm{S}^{\prime} \mathrm{s}$ belief is safe iff in nearly all (if not all) nearby possible worlds in which $S$ continues to form her belief about the target proposition in the same way as in the actual world the belief continues to be true. (See here Pritchard 2007a: 6)
} 
A safety theory of knowledge would be tailor-made to accommodate ALC, but almost immediately, such a theory looks doomed when faced with the task of accommodating AC. After all, does anything about whether one's cognitive success did or didn't arise through her exercise of cognitive abilities really follow from the mere fact that a belief counts as safe in virtue of having certain modal properties?

Consider here Bonjour's (1985) True Temp case; here, True Temp's beliefs count as paradigmatically safe because they are invariably true given how they are formed (i.e. by a thermometer that implants True Temp with always only correct beliefs about the present temperature). But also because of the way True Temp forms his beliefs, he fails to meet the necessary condition on knowledge imposed by (AC). After all, True temp is not exercising his "ability" to acquire the truth ${ }^{8}$ about the temperature any more than he would be exercising his "ability" to be struck by lightning every 25th of December (if, say, a peculiar demon always struck him with lightning on that day, but each time only because it happened to amuse him to do so). Because satisfying ALC does not ensure satisfying AC, a modal account of knowledge is a poor candidate as a theory that could satisfy both ALC and AC.

That said, let's consider whether the sort of proposal that would (at least prima facie) seem best equipped to accommodate AC (i.e. virtue-theoretic approaches, such as Sosa's, Greco's or Zagzebski's) is capable of accomodating the ALC constraint. This turns out to be a perplexing matter.

While it's not at all prima facie obvious that satisfying the ability constraint (AC) would be in itself enough to also ensure that the anti-luck constraint (ALC) on knowledge is satisfied, it's also not prima facie obvious that it couldn't be enough. Pritchard $(2007,2009,2010,2011)$ has taken an especially bold stance on this score. He denies not only that satisfying ALC entails satisfying AC, but also (quite importantly) he denies that satisfying AC entails satisfying ALC. Here's Pritchard:

Just as there is no formulation of the ability condition that can obviate the need for an anti-luck condition, so there is no formulation of the anti-luck condition that can obviate the need for an ability condition. (Pritchard 2010: 54)

Call this idea Pritchard's Independence Thesis:

Independence Thesis: Satisfying either AC or ALC does not entail that the other is satisfied.

If independence is true, then (as Pritchard is astutely aware) this really would appear bad for the prospects of robust virtue-theoretic (VE) accounts of knowl-

\footnotetext{
${ }^{8}$ We can't credit Temp's having gotten the truth to any cognitive ability Temp has. Consider here that Temp lacks any sort of voluntary control over (or even awareness of) his temperaturebelief-forming methods. After all, when one wants to know the temperature and finds it out, this is something we could credit to their abilities only if there was something the agent was able to do to learn the truth. There is clearly nothing True Temp can intend to do to learn the truth. The truth just 'comes' to him involuntarily, or so the example has it.
} 
edge. After all, VE accounts define knowledge exclusively in terms of the relationship between an agent's getting to the truth and the exercise of her cognitive ability that gives rise to it ${ }^{9}$. That relationship, for the VE proponent, is what is essential to knowing. If no fact about the relationship between an agent's believing truly and her having exercised cognitive ability is enough in itself to ensure that the virtuously formed true belief she has is not veritically lucky (i.e. lucky in a way that is incompatible with knowledge), then it would follow that virtue-theoretic accounts of knowledge-those which put forward an analysis of knowledge exclusively in terms of the ability constraint (AC)-are false.

On Pritchard's preferred view, what is needed to accommodate the ability and anti-luck constraints on an account of knowledge is a dual-condition view - one that requires for knowledge the satisfaction of both the ability and anti-luck constraints on knowledge and which, unlike virtue-theoretic approaches (hereafter VE), is premised upon Independence. Writes Pritchard:

I call the view that I have in mind, which constitutes a new theory of knowledge, anti-luck virtue epistemology...What is essential to anti-luck virtue epistemology is thus that it incorporates two conditions on knowledge, an anti-luck condition and an ability condition, and that it accords each condition equal weight in the sense that they are each answering to a fundamental intuition about knowledge (2010: 50, 54).

Pritchard's argument for anti-luck virtue epistemology has three central premises ${ }^{10}$. The first two are AC and ALC. The third is the Independence thesis, the thesis that neither AC nor ALC entail the other. From this Pritchard gets, as a conclusion from (1)-(3), his dual-condition anti-luck virtue epistemology.

\section{Pritchard's Master Argument}

1. Ability (constraint) on knowledge (AC): $S$ knows that $p$ only if $S^{\prime}$ s getting to the truth about whether or not $p$ results from the exercise of $S^{\prime} \mathrm{s}$ cognitive ability (or abilities).

2. Anti-luck constraint (ALC): $S$ knows that $p$ only if $S^{\prime}$ s getting to the truth about whether or not $p$ is not veritically lucky.

3. Independence: Satisfying either AC or ALC does not entail that the other is satisfied.

\footnotetext{
${ }^{9}$ Here see Pritchard 2010, ch. 4: 50 for a discussion of RVE and how it differs from what he calls modest virtue epistemology.

${ }^{10}$ Pritchard also appeals to some other considerations, most notably, considerations about the value of knowledge and about, following Craig (1990), the etiology of the concept of knowledge, which he draws from in making a presumptive case in favour of ALVE. It is beyond my aim here to challenge Pritchard on all these points. My focus will be instead on what function as core premises in his argument for ALVE-premises that his argument for ALVE depends on. And so I'm setting aside considerations he draws attention to about how his conclusion is compatible with certain theoretical desiderata.
} 
4. Therefore, Anti-luck Virtue Epistemology (ALVE): $S$ knows that $p$ only if: (i) AC is satisfied; (ii) ALC is satisfied ${ }^{11}$.

For the sake of what follows, I won't be taking issue with premises (1) and (2) of his argument; these are premises that Pritchard grants from the outset no less than do the defenders of the virtue-theoretic programme he is criticizing: what we're committed to by accepting (1) and (2) is just a recognition that the ability and anti-luck intuitions each capture an essential feature of knowledge and that their associated constraints on an analysis of knowledge are ones that a plausible theory must countenance. And so I won't then be challenging the common ground Pritchard has with his VE opponents. Instead, what I'll be turning a critical eye to is premise (3) - the Independence Thesis. This is where the heart of Pritchard's argument lies.

\section{Pritchard's Independence Thesis}

\subsection{The argument}

What is Pritchard's argument for the Independence Thesis-the crucial premise in his master argument? The Independence thesis follows straightforwardly from two premises, each which rejects one direction of entailment between AC and ALC.

\section{Pritchard's Independence Argument}

(I1) Satisfying the anti-luck constraint (ALC) does not entail that the ability constraint (AC) is satisfied.

(I2) Satisfying the ability constraint (AC) does not entail that the anti-luck constraint (ALC) is satisfied.

(I3) Independence: Satisfying either AC or ALC does not entail that the other is satisfied.

Let's look first at (I1), which denies the entailment from ALC to AC. As my discussion of the True Temp case in the previous section shows, I have no problem at all accepting premise (I1). What Pritchard himself (I think rightly) supposes in defense of (I1) is that:

\footnotetext{
${ }^{11} \mathrm{My}$ articulation of Pritchard's ALVE as consisting two necessary conditions on knowledge is consistent with how Pritchard lays out the key elements of his view (Ch. 3 pp. 38-54) though I take note that he has at places backtracked away toward something much weaker. In $\S 3.5$ of Ch. 3, Pritchard questions whether ALVE constitutes a reductive theory of knowledge. He admits that 'the default reading of the view is as offering a reductive account' (59) while also conceding that it's possible to read his account as non-reductive. He opts ultimately to take 'a liberal view on this issue' (59). Given that he has not given any positive arguments for reading his account as non-reductive- he only mentioned the possibility that we might find that it could be (59)-I'm electing to read him more at face value, as offering at least two strong, separate, and non-mutually entailing necessary conditions on knowledge.
} 
...it is inevitable that there will be cases in which there are true beliefs which exhibit the required modal properties to ensure that they are not lucky in the relevant sense and yet which are not formed as a result of the agent's cognitive abilities. (2010: 54)

No objections here. The interesting premise in Pritchard's Independence Argument, though, is not (I1), but (I2). Quite a bit rides on whether (I2) is true, after all. If it is not, then Pritchard must give up Independence, and if he gives up Independence, then his master argument for anti-luck virtue epistemology dissolves.

\subsection{Pritchard's motivations for premise (2): understanding cog- nitive achievement}

Before directly assessing the case Pritchard advances for (I2) in his Independence Argument, it will be appropriate to introduce an idea central to Sosa's (2007; 2009) and Greco's (2006; 2010) recent virtue-based accounts of knowledge and which functions importantly in Pritchard's critique of virtue epistemologypart of which he takes as his key support for (I2). The idea I have in mind here is that of cognitive achievement. We can understand cognitive achievements best by considering, as Sosa (2007) has in particular, achievements more generally. For Sosa an achievement in some domain of endeavour $D$ requires not only a $D$-success and the exhibition of some $D$-related ability, but that the $D$-success must be because of the manifestation of the $D$-ability.

Take as an example here archery-an analogy to the domain of cognitive endeavour which Sosa uses often. If, say, a drunken, blindfolded archer hits a difficult target, we count his shot as a successful shot. But we do not label the archer's success an achievement-to be an achievement, the archer must also shoot his arrow skillfully, in a way that involves the manifestation of some archery-related competence. But even this is not enough. Suppose the archer skillfully fires an arrow at a target, but due to an unfortunate gust of wind, the arrow is blown badly off target. At the last minute, though, another more fortuitious gust of wind blows the arrow back on line and the archer (luckily) hits his designated target. Here, the archer is successful and manifests skill in his shot; however, his success is not appropriately because of his skill, but because of the lucky gust of wind.

Achievement requires more than just compresence of success and skill: the success must be because of the skill being exercised. Let's move now to the cognitive arena, where-to extend the analogy-our cognitive performances (i.e. beliefs) are successful when they hit the mark of truth. ${ }^{12}$ The key idea, especially as found in Greco (2006; 2010) and Sosa (2007), is that a cognitive achievement requires that the agent's having been cognitively successful (i.e. believing truly on a given matter) is relevantly because of one's having exercised

\footnotetext{
${ }^{12}$ It is not being suggested here that beliefs are aimed, intentionally, at particular truths. The dictum "truth is the aim of belief" captures, in the sense that is relevant here, the idea that truth is the success criterion for belief. It is with this in mind that we might say that truth is the aim of belief. For a useful discussion on this point, see Engel (2005).
} 
cognitive ability. Pritchard's analysis of how to interpret the relevant notion of 'because' here as it functions in the achievement thesis is I think a plausible one:

How are we to read the 'because of' relation here? There is as yet no consensus amongst...virtue epistemologists on this score, but the most developed view in the literature in this regard due to Greco (2007a; 2007b) takes the causal explanatory line that true belief is because of an agent's cognitive abilities when it is primarily creditable to the agent that her belief is true. (Pritchard 2010: 26)

Following Pritchard, and setting aside presently the details of Greco's causalexplanatory line (which, for the purposes of being ecumenical, we need not take on board), I offer the following as a fair articulation of the cognitive achievement thesis ${ }^{13}$ we find at the very heart of virtue epistemology.

Cognitive Achievement: $S^{\prime}$ s true belief that $p$ constitutes a cognitive achievement if and only if $S^{\prime}$ s believing $p$ truly is primarily creditable to $S^{\prime}$ s cognitive abilities.

What stands as the core maneuver in the account of knowledge the VE programme offers is that the conditions necessary and sufficient for cognitive achievement are also necessary and sufficient for knowledge. The idea advanced by VE accounts of knowledge then is that knowledge consists essentially in cognitive achievement. Thus, the VE analysis of knowledge can be abbreviated as follows:

Virtue epistemology (VE): $S$ knows that $p$ if, and only if, $S^{\prime}$ s believing $p$ truly constitutes a cognitive achievement.

One side of the VE biconditional makes a claim about what is necessary for knowledge. Call this the VE-N:

VE Necessity Thesis: (VE-N): $S$ knows that $p$ only if $S^{\prime}$ s true belief that $p$ constitutes a cognitive achievement.

Contrast this now with the sufficiency claim also implied by VE:

VE Sufficiency Thesis: (VE-S): $S$ knows that $p$ if $S^{\prime}$ s true belief that $p$ constitutes a cognitive achievement. ${ }^{14}$

\footnotetext{
${ }^{13}$ Lackey $(2003,2007)$ has interpreted this thesis slightly differently, as one that claims that, for cognitive achievement, the agent's getting the truth on a given matter must be creditable to the agent herself-as opposed to the agent's cognitive abilities. Lackey represents the cognitive achievement view this way when attacking it with testimonial-based counterexamples. I take it that the articulation I use here, which expresses what is to which the cognitive success is to be primarily credited as cognitive abilities, (as Pritchard thinks) more in line with the standard way of thinking about the view-as Greco represents it in his own defence of RVE and as Sosa defends his own view in his recent books that arose from his Locke Lectures.

${ }^{14}$ It is worth noting here that Greco $(2003 ; 2010)$ has argued that something like the VE-S is correct, as he takes it that cognitive achievement is sufficient for knowledge and also that the right
} 
Between the two theses, the necessity claim (see Lackey 2003; 2007) has received considerably more critical attention than has the sufficiency claim. Pritchard has, more or less, accepted a version ${ }^{15}$ of Lackey's testimony-style argument against VE's necessity claim (VE-N). For our purposes, it doesn't much matter whether he is right on this point. If he is right (that VE-N is false) then the upshot is that he'll have undermined the VE thesis-without having supported any premise of his own ALVE master argument. Equally, if his case for rejecting VE-N is wrong, then this doesn't hurt his own argument either. The stakes are very different with respect to VE-S. For Pritchard, so much more is riding on whether his reasons for rejecting VE-S are good ones. This is because the argument he makes against VE-S is also the very same argument he takes to support the crucial Premise (I2) of his Independence Argument-the premise on which we've determined that, for Pritchard, the case for ALVE is now riding.

Pritchard's strategy for rejecting VE-S and supporting Premise (I2) is one where he'll argue, by way of example, for the following position: that cognitive achievement is compatible with knowledge-undermining (veritic) luck. This would be, (to put it mildly), a very important result for him.

For one thing, if he could establish the compatibility of cognitive achievement and environmental luck, he could use this to reject VE-S outright by arguing that it shows cognitive achievement to be insufficient for knowledge. More importantly, though, if Pritchard can show that cognitive achievement is compatible with knowledge-undermining (veritic) luck, then this would secure him his 'lynchpin premise'-Premise (I2) - he'll have shown that satisfying the ability constraint $(\mathrm{AC})$ does not entail that the anti-luck constraint (ALC) is satisfied. A lot then rides then on whether Pritchard is right that cognitive achievements are compatible with knowledge-undermining veritic luck. Let's call this key point Pritchard will be arguing for the compatibility thesis:

Compatibility thesis: Cognitive achievements are compatible with knowledge-undermining veritic luck.

Before proceeding, let's piece together the big picture. Recall first Pritchard's Master Argument for ALVE.

\section{Pritchard's Master Argument for ALVE:}

connection between an agent's exercise of intellectual ability and getting to the truth is enough to exclude knowledge undermining luck as well as vouchsafe cognitive achievement. There are a lot of merits to Greco's view, however, a problem-which I have discussed elsewhere in Carter 2011) is that Greco endorses a "lack of control" account of luck, which makes both the notions of "credit" and "luck" turn upon his contextualist treatment of causal explanation. For a discussion of the downfalls of a lack-of-control account of luck, see Lackey 2008.

${ }^{15}$ Pritchard (2010) uses the example of 'Jenny', a spin off Lackey's original (2003) rejection of the necessity condition, to make his own nuanced argument against the necessity of cognitive achievement for knowledge. The key spot where Pritchard parts ways with Lackey is that Pritchard (unlike Lackey) takes the relevant notion of credit at play to be Greco's-that cognitive achievements require that the relevant cognitive successes be primarily creditable to the agent's intellectual abilities. Lackey makes her case against the necessity condition by supposing that for cognitive achievement what is relevant is that the cognitive access be attributable to the agent. For Pritchard's discussion on these points, see his 2010, Ch. 2, § 2.6 (esp. pp. 38-39). 
1. Ability (constraint) on knowledge (AC): $S$ knows that $p$ only if $S^{\prime}$ s getting to the truth about whether or not $p$ results from the exercise of $S^{\prime}$ s cognitive ability (or abilities).

2. Anti-luck constraint (ALC): $S$ knows that $p$ only if $S^{\prime}$ s getting to the truth about whether or not $p$ is not veritically lucky.

3. Independence: Satisfying either AC or ALC does not entail that the other is satisfied.

4. Therefore, anti-luck virtue epistemology: $S$ knows that $p$ only if: (i) AC is satisfied; (ii) ALC is satisfied.

Because (1) and (2) are plausible, it's Independence upon which his argument rides. And for that premise, we saw that the argument was:

\section{Pritchard's Independence Argument:}

(I1) Satisfying the anti-luck constraint (ALC) does not entail that the ability constraint (AC) is satisfied.

(I2) Satisfying the ability constraint (AC) does not entail that the anti-luck constraint (ALC) is satisfied.

(I3) Independence: Satisfying either AC or ALC does not entail that the other is satisfied.

Now in his argument for Independence, we said that I1 was plausible. And so his argument for ALVE rides on I2. And Pritchard's support for I2 is the compatibility thesis. So if the compatibility thesis is false, Pritchard's anti-luck virtue epistemology is unsound.

\section{Pritchard's argument for the compatibility thesis}

At this point, before we consider Pritchard's argument for compatibility, it will be important to make yet a new distinction, one which will highlight the difference between two kinds of knowledge undermining (veritic) epistemic luck. This distinction functions prominently in Pritchard's case for compatibility. As I see it, the most straightforward way to capture the relevant distinction here is to consider what separates would-be knowers epistemically in Gettier cases-such as Gettier's own original Smith/Jones case-from the would-be knowers in barn façade cases-i.e. cases where you correctly believe There's a barn when pointing to a barn that, unbeknownst to you, is the lone real barn in a valley salted with facades. Even though Gettier-style and barn-façade cases are ones where the hero believing truly is lucky (i.e. the hero's belief comes out false in a wide class of nearby worlds where she forms her belief as she does in the actual world ${ }^{16}$ ) and therefore lacks knowledge, the epistemic situations we find our Gettier and barn façade heroes in are slightly different.

${ }^{16}$ Respectively, in both cases. 
In order to see this more clearly, consider that in the original Gettier (1963) case of Smith and Jones, Smith's own intellectual efforts had little to nothing to do with why it is that Smith's belief The man who will get the job has ten coins in his pocket is true ${ }^{17}$. Here, the sort of luck at play is what Pritchard calls intervening luck. On his view, intervening luck is a variety of veritic epistemic luck that undermines knowledge by, as it were, intervening (as Unger (1975) has put it) betwixt the man and the fact. (Pritchard 2005). Put another way: what we have in these cases is a clear and obvious disconnect between the agent's intellectual efforts and the success of her belief. The cognitively successful (true) belief is something the cognitive abilities of the agent had little to do with ensuring. Consequently, in the Gettier-style cases, where intervening veritic luck is what's at issue, we are inclined (strongly) to deny that the agent's cognitive success is by any stretch one that is primarily creditable to the agent's cognitive ability. And so proper Gettier-style cases are not cases where cognitive achievements are plausibly present.

That said, consider that knowledge-undermining (veritic) luck is also at play in barn façade cases. But the veritic luck at play here does not 'intervene', as it were, between the man and the fact in the way it did in Gettier-style cases. After all, in barn facade cases, the agent's perceptual abilities would seem directly responsible for her target belief There's a barn.

Let's consider now Pritchard's own preferred articulation of the barn façade case; I'm using here his recent (2010: 34) presentation of it:

Barney forms a true belief that there is a barn in front of him by using his cognitive abilities. That is, unlike a Gettier-style caseBarney does not make any cognitive error ${ }^{18}$ in forming his belief in the way that he does. Accordingly, we would naturally say that Barney's cognitive success is because of his cognitive ability and so we would, therefore, attribute a cognitive achievement to Barney. That is, his cognitive success in this case is primarily creditable to his cognitive abilities... The twist in the tale, however, is that, unbeknownst to Barney, he is in fact in 'barn façade county' where all the other apparent barns are fakes. Intuitively, he does not have knowledge in this case because it is simply a matter of luck that his belief is true. (Pritchard 2010: 34)

Though we've said that when an agent's cognitive success is infected by Gettierstyle (intervening) epistemic luck, the cognitive success would not be a cognitive achievement, we have here a different intuition, as Pritchard notes. Though Barney's getting the truth here is veritically lucky (and thus not knowledge), this fact does not seem (as it did in Gettier cases) as though it should prevent us from nonetheless attributing Barney's acquisition of a true belief primarily to

\footnotetext{
${ }^{17}$ That his belief 'the man who will get the job has 10 coins in his pocket' was true owed entirely to the off-chance that a different man than he thought would get the job did (himself) and that he-being that man-happened to have 10 coins in his pocket.

${ }^{18}$ For instance, the error of reasoning through a false belief.
} 
his cognitive abilities-and so ruling that his getting to the truth as he did here would seem to constitute a cognitive achievement. Here's Pritchard:

Cases like that of 'Barney' illustrate that there is a type of knowledgeundermining epistemic luck, what we might call environmental epistemic luck-which is distinct from the sort of epistemic luck in play in standard Gettier-style cases... in cases of environmental epistemic luck like that involving Barney, luck of this intervening sort is absentBarney really does get to see the barn and forms a true belief on this basis-although the epistemically inhospitable nature of the environment ensures that his belief is nevertheless only true as a matter of luck such that he lacks knowledge.

Finally, elsewhere, Pritchard sums up the features of the case that he takes to be important for establishing compatibility.

...the agent [Barney] fails to have knowledge because his belief is subject to knowledge-undermining epistemic luck but... nonetheless (and unlike Gettier-style cases), the agent does exhibit a cognitive achievement (i.e., the agent's true belief is primarily creditable to his cognitive abilities). (Pritchard 2009: 47)

An obvious point is that if Pritchard's diagnosis is correct here, then he will have proved compatibility-and therefore, it would seem that all is in place for him to prove Independence and, accordingly, ALVE. And so what we want to know now, then, is whether environmental luck, such as the luck that undermines knowledge in barn façade cases, is really compatible with cognitive achievements, as Pritchard is supposing it to be here ${ }^{19}$.

This suggestion has admittedly a lot going for it. After all, if we consider Pritchard's often-used case (which I'll be revisiting more critically in \$7) of an archer who shoots skillfully and successfully at a target which is itself (unbeknownst to the archer) the only one not surrounded by a forcefield that would have deflected his arrow (see, eg., Pritchard 2009: 34), it seems right to call what the archer has done an achievement, even though the environmental luck present in the situation undermines the safety of his success.

And further, to Pritchard's credit, it seems right to credit Barney and the archer for their lucky successes even though we're not inclined to credit Smith for his lucky success in the Gettier-style case, when intervening luck undermined the safety of his success. These considerations indeed suggest that (knowledge-undermining) environmental luck is compatible with cognitive achievements even though intervening, Gettier-style luck is not. Despite all of

\footnotetext{
${ }^{19}$ Interestingly, this is a view that is shared to some degree by Sosa (2007) per his discussion of the kaleidoscope perceiver. (Sosa 2007: 100-101) Sosa's kaleidoscope perceiver has, according to Sosa, an apt belief (correct due to a manifestation of competence) despite the fact that the belief could have easily been false. His view is that animal knowledge, which only requires apt belief, can persist in such circumstances, whilst reflective knowledge, which is apt belief aptly noted (or apt belief in one's first-order apt belief) is undermined.
} 
this, though, I think Pritchard's assessment on this score is mistaken and that, consequently, the motivation for his central argument unravels as a result.

\section{Part II}

\section{Anti-luck virtue epistemology disrobed}

\section{Two senses of believing truly: agent-focused and belief-focused}

My argument here requires that we take, as a starting point, a key idea developed upon in the in opening section (\$1.1) of this paper: that luck undermines knowledge not when it's a matter of luck that you have some true belief that you do (as was the case with James and Emma) but when it's a matter of luck that the belief you have is true. What this revealed, on closer consideration, is that the cognitive success that occurs when one's belief is true is a success that lends itself to two importantly different ways of reading what is constitutive of the 'believing truly' success, and so two importantly different ways of reading what we're concerned with insofar as it would depend on luck. On the first sense which, in line with my discussion in $\S 1$ I'll call the agent-focused sense, it is that I have a true belief $(p)$ that stands as the relevant cognitive success.

Agent-focused sense (of the cognitive success of believing truly): The cognitive success consisting in the fact that I have some true belief (p).

Here the subject of the that clause indicating the relevant success is " $\mathrm{I}$ "agent. Understood in the agent-focused sense, the cognitive success of believing truly is articulated in terms of what the (epistemic) agent has - namely a true belief. Importantly, it doesn't matter for knowledge whether the success of my believing truly, construed in the agent-focused sense, depends on luck. For example, if your having some true belief $(p)$ fails to occur in a wide class of nearby possible worlds, you can nonetheless still know $p$, as Emma did, when she could have easily had a lecturer from whom whe would have never encountered the fact about Napoleon that she happens to know. Such cases are ones where your having the true belief you do depends on situational luck (i.e. you could have easily not had that true belief). It doesn't matter for knowledge, then, whether my believing truly, construed in the agent-focused sense, depends on luck. In the second sense, which for ease of reference I'll call the belief-focused sense, it is that my belief is true that stands as the relevant cognitive success. 


\section{Belief-focused sense (of the cognitive success of believing truly):}

The cognitive success consisting in the fact that my belief is true.

The subject of the "that clause" that indicates the relevant success here is not "I", the agent, but my "belief." Understood in the belief-focused sense, the cognitive success of believing truly is articualted in terms of what my belief has as a truth value rather than what I have attained (i.e. a true belief) qua believer. Importantly, it does matter for knowledge whether the success of my believing truly, construed in the belief-focused sense, depends on luck. For example, if that my belief is true is not the case in a wide class of near-by possible worlds where the relevant initial conditions for my having formed my belief are the same as they are in the actual world, then (obviously) the following will be the case: there will be a wide class of near-by possible worlds in which I continue to believe the target proposition, and the relevant initial conditions for the formation of my belief are the same as in the actual world, and yet my belief is false. Thus, here my belief counts as veritically lucky, and I fail to know $p$. Clearly, then, it does matter for knowledge whether my believing truly, construed in the belief-focused sense, depends on luck.

That said, consider again that on the VE account of knowledge, what is essential to knowing is cognitive achievement. And intrinsic to cognitive achievements is a relation between cognitive success and cognitive ability. Specifically, the thought was that, for an agent $S$ and a belief $p, S^{\prime}$ s believing $p$ truly constitutes a cognitive achievement if and only if $S^{\prime}$ s believing $p$ truly is primarily creditable to $S^{\prime}$ s cognitive abilities. How should the cognitive success consisting in one's believing $p$ truly be interpreted here, as the success element of a cognitive achievement?

This brings us to the crucial point that Pritchard has missed: believing truly could (as we've just seen) pick out either of two very different cognitive successes-one which would matter for knowledge whether it owes itself to luck (or, presumably, ability) and one which would not. A pressing question becomes the following: which is it, the agent-focused or the belief-focused sense of the success of believing truly that the VE theorist takes to be the relevant one at play when she identifies knowledge with cognitive achievement?

Let's take the luck discussion as our precedent. In our discussion of knowledge and luck, what we saw was that it mattered for knowledge only that the success of believing truly, in the belief-focused sense, didn't depend on luck. It was shown to be irrelevant to knowledge whether the success of believing truly, in the agent-focused sense, depended on luck ${ }^{20}$. Based on these observations, it seems prima facie plausible to think that the belief-focused rather than the agent-focused sense of believing truly picks out the sense of this cognitive success that matters for knowledge whether it arises through ability (i.e. is primarily creditable to our cognitive abilities). Let's see now if our hunch is right.

\footnotetext{
${ }^{20}$ If it did, then we might casually note that it's a matter of situational luck that we have some true belief that we do. Nothing can be inferred from this fact regarding whether we count as knowing.
} 


\section{Cognitive Achievement Revisited}

Consider again the cognitive achievement thesis:

Cognitive Achievement: $S^{\prime}$ s true belief that $p$ constitutes a cognitive achievement if and only if $S^{\prime}$ s believing $p$ truly is primarily creditable to $S^{\prime}$ s cognitive abilities.

As we've said, the cognitive achievement thesis, like the claim that one's believing truly cannot depend on luck, admits of either of two distinct interpretations. One interpretation reads 'believing $p$ truly' as an agent-focused success, and so holds knowledge to require that this agent-focused success be primarily creditable to the agent's cognitive abilities. The other interpretation reads 'believing $p$ truly' as a belief-focused success, and so holds knowledge to require that this belief-focused success be primarily creditable to the agent's cognitive abilities. We have then two rival versions of the cognitive achievement thesis, one which holds (for cognitive achievement) as primarily creditable to cognitive abilities an agent-focused success (CA-A) and the other which holds (for cognitive achievement) as primarily creditable to cognitive abilities a belief-focused success (CA-B):

Cognitive achievement (agent-focused cognitive success) CA-A: $S^{\prime}$ s true belief that $p$ constitutes a cognitive achievement if and only if that $S$ has a true belief that $p$ is primarily creditable to $S^{\prime}$ s cognitive abilities.

Cognitive achievement (belief-focused cognitive success): CA-B: $S^{\prime}$ s true belief that $p$ constitutes a cognitive achievement if and only if that the belief $S$ formed is true is primarily creditable to S's cognitive abilities.

So which of these two cognitive achievement accounts best captures what it is that the VE-theorist wants to say is necessary and sufficient for knowledge, CA-A or CA-B? Let's look first at CA-A, which contains the agent-focused interpretation of cognitive success. Bear in mind now some considerations relevant to which reading should be thought the most plausible one: First, the most prominent defenders of virtue-theoretic accounts of knowledge, Greco (2010), Zagzebski (1994; 1996) and with some caveats Sosa ${ }^{21}$ (2007; 2009), have all endorsed without revision the view that environmental luck - as is what's at play in barn façade cases-is incompatible with knowing. As a point of textual interpretation, then, if either one of CA-A and CA-B but not the other implied straightforwardly for the VE account that environmental luck is compatible with knowing, then ceterus paribus, we should read the canonical VE articulation of cognitive achievement as being the one free from this implication.

Secondly, and more importantly, we should bear in mind that our discussion of luck has already left us with a precedent for determining which characterisation of the success of believing truly would stand relevant to whether one

\footnotetext{
${ }^{21}$ Sosa holds this view regarding reflective knowledge, though not animal knowledge. See Sosa (2007).
} 
knows: this precedent is one we can extend from discussions of how knowledge (can't) depend on luck to relevantly similar discussions of how knowledge (must) depend on cognitive ability ${ }^{22}$. To make this point clear, let's take the ambiguously phrased 'believing $\mathrm{p}$ truly.' The anti-luck constraint tells us that:

(1) It matters for knowledge whether believing $p$ truly depends on luck

The ability constraint tells us that (2) is true.

(2) It matters for knowledge whether believing $p$ truly depends (in the sense of being primarily creditable to) on cognitive ability.

Wouldn't it be odd if 'believing $p$ truly' were one thing when it's what it is that Pritchard thinks knowledge requires can't depend on luck and another thing when it's what it is that he thinks knowledge requires does depend on cognitive ability? After all, it's plausible to suppose that, in all relevant respects, the same thing that could depend on luck could also depend on cognitive ability or skill. It would seem prima facie quite counterintuitive to deny this.

Sosa (2007), in a discussion of testimonial knowledge and credit, has echoed this sort of point and, accordingly, he gestures strongly in favour of the CA-B reading of cognitive achievements. According to Sosa:

The error resides... in supposing that what explains there being my true belief is what explains why my belief is true. (Sosa 2007: 96)

Sosa (2007) also weighs in unambiguously in favour of the CA-B reading elswhere in a discussion about apt belief ${ }^{23}$.

What must be attributable to the competence is not just the belief's existence but its correctness. (Sosa 2007: 33)

Bearing these considerations in mind, let's now turn to look at our first reading of cognitive achievement-CA-A, which (recall) claimed that $S^{\prime}$ s true belief that $p$ constitutes a cognitive achievement if and only if that $S$ has a true belief that $p$ is primarily creditable to $S$ 's cognitive abilities. Let's see now see whether, on this reading, the theory that knowledge $=$ cognitive achievement commits itself to the compatibility of knowledge and (veritic) environmental luck. To this end, let's revisit the Barney case. On CA-A, Barney's cognitive success of believing $p$ truly should be read as: the success that he (Barney) had a true belief $(p)$. Is this success primarily creditable to his abilities? Unlike in Gettier cases, where it is intuitive to deny that that the agent has a true belief is something the agent's own

\footnotetext{
${ }^{22}$ This is because what matters about the cognitive success with respect to what knowledge requires can be framed in terms of a dependence relation that stands between cognitive success and luck in a way analogous to the relevant dependence relation at play between cognitive success and ability.

${ }^{23}$ This discussion is found in Sosa's (2007) second lecture, "A Virtue Epistemology."
} 
intellectual efforts had anything much to do with, we look here at Barney's own cognitive abilities as what's most salient in explaining that he (Barney) had a true belief. Of course, Barney's belief could have easily been false (as he could have easily formed his belief about a barn façade), and so his belief is infiltrated by knowledge-undermining environmental luck and is thus not knowledge. So on the CA-A reading of cognitive achievement, cognitive achievements do seem compatible with knowledge undermining luck, and ipso facto, knowledge and cognitive achievements defined in this way come apart-the exact result Pritchard reached in his argument against the view that knowledge $=$ cognitive achievement.

We've seen though that, due to the textual as well as symmetry-related ${ }^{24}$ considerations, that it would be quite odd for CA-A to be the version of the cognitive achievement thesis Pritchard actually needs to argue against. After all, we said it's plausible to suppose that whatever the relevant success it is that we think matters for knowledge whether it depends more or less on luck would also be one that should matter (for knowledge) whether it depends more or less on cognitive ability or skill. CA-A, however, captures the cognitive achievement thesis only if we go the much less plausible route and suppose that (for knowledge) what can't depend on luck is a success that's not the same success ${ }^{25}$ we have in mind when thinking that, when we know, it will depend on our cognitive abilities.

A further strike against the thought that Pritchard's target should be CA-A is that, as it was mentioned, none of the key defenders of the view Pritchard is challenging actually accepts that knowledge is compatible with environmental luck - which we saw was a straightforward and obvious implication of reading the cognitive achievement thesis alongside (as Pritchard reads it) a notion of agent-focused cognitive success. Textual support as well as our intuitive consistency argument then both point to the thought that the claim the virtue epistemologist is making about knowledge is something other than what Pritchard has actually challenged.

Let's look now at the cognitive achievement thesis articulated with belieffocused articulation of the cognitive success relevant to knowledge. Again, this is the articulation that stipulates the cognitive success for which it matters for knowledge whether it depends on ability as being the same that we saw mattered for knowledge whether it depended on luck. On CA-B, Barney's cognitive success of believing $p$ truly should be read as: the success that the belief Barney formed $(p)$ was true. Now if it turns out that, in the Barney case where environmental luck undermines knowledge, this characterization of the cogni-

\footnotetext{
${ }^{24}$ The relevant cognitive success that matters for knowledge whether it depends on luck should be the same cognitive success that would matter for knowledge whether it owes to ability. In this sense, I am suggesting there should be a symmetry.

${ }^{25}$ One success answerable to the description of "believing $p$ truly" is articulated in terms of a "that clause" which takes the agent as the clause's subject and for which the clause's verb (has) is an action verb. So this success consists in someone having something. Another success consists in something being a certain way-namely my belief being true. This success is articulated in terms of a "that clause" that takes my belief as the clause's subject and for which the clause's verb (be) is a linking verb.
} 
tive success of believing $p$ truly is nonetheless primarily creditable to Barney's cognitive ability (as the agent-focused characterization was), then the fact that Pritchard dismissed the cognitive achievement thesis without ever challenging this particular formulation of it will be a moot point.

But if, on the other hand, CA-B is shown not to be compatible with the knowledge-undermining environmental luck at play in the Barney case, then since we already have a presumptive case for thinking that it is cognitive achievement underscored by the belief-focused cognitive success condition that knowledge would most plausibly be understood in terms of, then the game changes radically. Pritchard will have established environmental luck to be compatible only with the less plausible of our two versions of the cognitive achievement thesis, and with respect to the more plausible version, his challenge will have been shown not to work.

\section{Cognitive Achievement and Environmental Luck}

In order to now make my case that the more plausible way of presenting the cognitive achievement thesis, CA-B, is clearly not compatible with environmental luck (of the sort that undermines knowledge, i.e., in barn façade cases), I want to consider again a version of the archery case that Pritchard himself has frequently used in papers to illustrate what he takes to be a non-epistemic counterpart to the barn façade case. Imagine an archer, Archie, who:

... selects his target from a range of potential targets entirely at random before skilfully firing his arrow and hitting the target. Let us stipulate that the success here is not subject to Gettier-style luck, in that nothing intervenes between the ability and the success, such as the two freak gusts of wind which fortuitously cancel each other out that were described above. Nevertheless, the success is lucky because, unbeknownst to Archie, all of the other targets that he could have fired at contained forcefields which would usually repel arrows. Fortunately, Archie just happened to fire at the one target that lacked such a forcefield. (Pritchard 2008: 10)

As we would suspect, Pritchard thinks that here in the domain of action, (archery) achievement is compatible with environmental luck undermining the safety of the success.

I take it that we have a strong intuition in this case that even though the success in question is lucky, this does not prevent Archie from exhibiting a genuine achievement. Indeed, we would naturally say that his success-his hitting of the target-is because of his skills at archery... Environmental luck, it turns out, is compatible with genuine achievements, unlike Gettier-style luck. (Pritchard 2008: 10) ${ }^{26}$

${ }^{26}$ My italics. 
Notice how Pritchard defines Archie's success, which he takes to be primarily creditable to Archie's skill in a way sufficient for achievement:

Archie's success: "His hitting of the target" (2008: 10)

I have no problem with granting Pritchard what he says here, that the success consisting in Archie's hitting the target is most saliently explained by his having skillfully shot his arrow. We may note importantly that the success here is articulated so as to be agent focused. To see this, just consider how "his hitting of the target" would stand to follow a 'that clause'. The success of "his hitting of the target" is the success that____ ; and here we say: that he hit the target. The subject of the clause representing the success at issue for Pritchard is the agent (the archer). ${ }^{27}$

But here in the case of Archie, there is a different way to think about the success consisting in his hitting the target, one that doesn't have us appeal to an agent-focused articulation of his success-and this different way will have us view his success in accordance with the way the CA-B version of the cognitive achievement thesis views the relevant cognitive success of believing some proposition truly. That said, let's recall that the belief-focused articulation of the success at issue made the belief the subject of the that clause. We said that, understood in the belief-focused sense, the cognitive success of believing truly is articulated in terms of what my belief takes as a truth value rather than what I have attained (i.e. a true belief) qua believer.

Now let's see what happens when we make the analogy to action. It can be pointed out quite generally that beliefs are successful just when true and archery shots are successful just when they hit the target. Parallel to the success articulated by the clause that the belief I formed was true (i.e. successful) is the success that the shot I fired hit the target (i.e. is successful). Dialectically, it's important to take stock of the fact that we did not take issue with Pritchard's claim that it is primarily creditable to Archie's archery skills that he had a successful shot $(\alpha)$. We can and should though take issue with the assertion that that the shot he fired was successful is primarily creditable to these same skills.

Admittedly, one treads on contentious ground when trying to offer positive conditions under which successes are primarily attributable to the relevant skills that give rise to them. Fortunately, to motivate my argument, I only need to propose a negative thesis that should be intuitive and uncontroversial-just a sufficiency claim with respect to the conditions under which a success (in any domain of endeavour) is something that would fail to be primarily creditable to the success-related skills of the performing agent in question. Call this (Not) Primarily Creditable (NC):

(NOT) Primarily Creditable (NC): That $S^{\prime}$ s $\phi$-aimed effort was successful is itself not primarily creditable to $S^{\prime} s \phi$-abilities if, holding

\footnotetext{
${ }^{27}$ Given what we concluded in the epistemic case when it was the agent-focused reading of the success condition on display, it is not surprising that in this case, which features an analogous sort of environmental luck, the agent-focused articulation of the relevant success is one we can naturally attribute (primarily) to the archer's abilities-generating an achievement that, as Pritchard, notes, seems entirely compatible with environmental luck that undermines the safety of the success.
} 
fixed the total contribution of S's $\phi$-abilities manifested in the actual world in $S^{\prime}$ s attempt to bring about $\phi$, most nearby worlds are worlds where $\mathrm{S}$ fails to bring about $\phi$.

$\mathrm{NC}$ is squarely in line with the way we make credit attributions for successes in ordinary language. Suppose Phil, a skillful golfer, fires a three-wood from 300 yards out, and the ball goes into the hole. Everyone congratulates Phil's skillful shot, though in the same breath, everyone (including Phil) knows it was just luck that the ball went in the hole at that range. This will always be so no matter how skillful one's golf shot (from that range) is. Though Phil's golf skills provided him with the ability to hit a clean, accurate shot at the pin, they play no role in explaining why the shot Phil hit found its way into the tiny hole-the subtleties of wind and bounce which steered his ball into the cup are ones over which he had no ability to ensure. Hence, as NC says, if we hold fixed everything Phil did skillfully with the aim of holing his shot, most nearby worlds are worlds where his shot does not go in the hole, but instead somewhere near it. 28

The same relevant point holds for Archie. Holding fixed the total contribution of Archie's archery abilities toward his goal of hitting a target with his shot, most nearby worlds are worlds where Archie, firing with the same skilful release as he does in the actual world (where he was successful) hits instead one of the forcefield targets instead, and so fails. Even if we grant Pritchard, then, that that Archie hit the target he did in the actual world is primarily creditable to his archery abilities, it remains that that the shot he fired was successful (hit a target) is not primarily creditable to his archery abilities.

We can make the natural move now to the epistemic case. Holding fixed the total contribution of Barney's cognitive abilities with respect to his truthaimed barn belief, most nearby worlds are worlds where the barn belief he forms is false. Just as Phil lacks the ability to ensure the wind and terrain would combine to put his skillful shot in the hole, Barney's perceptual beliefforming skills were insufficient for ensuring that the 'target' of his belief was a real barn, rather than any of the nearby facades.

And so it is not primarily creditable to Barney's cognitive abilities that the belief he has is true. The most plausible way to interpret the cognitive achievement thesis, then, is one according to which cognitive achievements are not compatible with environmental luck. This fact undercut's Pritchard's motivation for the $\sim(\mathrm{AC} \rightarrow \mathrm{ALC})$ leg of his independence thesis. ${ }^{29}$ And with the

\footnotetext{
${ }^{28}$ That the shot he fired went in is not primarily creditable to his abilities. What is creditable to his abilities is that he hit a clean, well-struck shot, with good distance-control, in the direction of the pin.

${ }^{29}$ Here, again, is the presentation of Pritchard's Independence Thesis (which I have challenged) within the context of his master argument for ALVE.
}

\section{Pritchard's Master Argument for ALVE:}

1. Ability (constraint) on knowledge (AC): $S$ knows that $p$ only if $S^{\prime}$ s getting to the truth about whether or not $p$ results from the exercise of $S^{\prime}$ s cognitive ability (or abilities).

2. Anti-luck constraint (ALC): $S$ knows that $p$ only if $S^{\prime}$ s getting to the truth about whether or 
independence thesis no longer in place, so falls any positive reason to think that the anti-luck and ability intuitions are countenanced better by Pritchard's dual-condition form of anti-luck virtue epistemology than by the VE proposals he has dismissed. Whether VE can accommodate the ability and anti-luck constraints on an analysis of knowledge is a live question.

\section{References}

[1] Bonjour, Lawrence (1985). The Structure of Empirical Knowledge, Harvard: Harvard University Press.

[2] Carter, J. Adam (2011). Radical Skepticism, Closure and Robust Knowledge, in The Journal of Philosophical Research, (forthcoming 2011).

[3] Craig, Edward (1990). Knowledge and the State of Nature: An Essay in Conceptual Synthesis. Oxford: Oxford University Press.

[4] Engel, Pascal (2005). "Truth and the aim of Belief, "in D. Gillies, ed. Laws and Models in Science, London: King's College Publications, 79-99.

[5] Gettier, Edmund (1963). "Is Justified True Belief Knowledge?" Analysis, Vol. 23, 21-23.

[6] Greco, John (2010). Achieving Knowledge, Oxford: Oxford University Press.

[7] - (2008). "What's Wrong with Contextualism?" Philosophical Quarterly, Vol. 58 (232): 416-43

[8] - (2006). "Virtue, Luck and the Pyrrhonian Problematic," Philosophical Studies, Vol. 130 (1): 9-34.

[9] —-(2006). "Knowledge as Credit for True Belief" in Michael DePaul \& Linda Zagzebski (eds.), Intellectual Virtue: Perspectives From Ethics and Epistemology, Oxford: Oxford University Press.

[10] Lackey, Jennifer (2008). "What Luck is Not" Australasian Journal of Philosophy 86 (2):255 - 267.

[11] Pritchard, Duncan. (2005) Epistemic Luck, Oxford: OUP.

not $p$ is not veritically lucky.

3. Independence: Satisfying either AC or ALC does not entail that the other is satisfied.

4. Therefore, anti-luck virtue epistemology: $S$ knows that $p$ only if: (i) AC is satisfied; (ii) ALC is satisfied. 
[12] - (2007). Anti-Luck Epistemology', Synthese 158 (2007), 27797

[13] — (2009a). Safety-Based Epistemology: Whither Now?', Journal of Philosophical Research, Vol. 34 (2009), 33-45

[14] - (2009b). 'Knowledge, Understanding and Epistemic Value', Epistemology (Royal Institute of Philosophy Lectures), (ed.) A. O'Hear, 19-43, (Cambridge UP, 2009).

[15] - (2010a). The Nature and Value of Knowledge: Three Investigations (with Adrian Haddock and Alan Millar, Oxford UP, 2010.

[16] — (2011). "Anti-Luck Virtue Epistemology," in Journal of Philosophy, (forthcoming 2011).

[17] Riggs, Wayne (2009). "Luck, Knowledge, and Control," in Epistemic Value, A. Haddock, A. Millar, \& D. H. Pritchard, eds. (Oxford: Oxford University Press, 2009)

[18] — - (2007). "Why Epistemologists Are So Down On Their Luck," Synthese 158, Vol. 3, November 2007.

[19] Sosa (2007) Apt Belief and Reflective Knowledge, Vol. 1, Oxford: OUP.

[20] - (2009). Apt Belief and Reflective Knowledge, Vol. 2., Oxford: OUP.

[21] Unger, Peter (1975). Ignorance: A Case for Skepticism, Oxford: Oxford University Press.

[22] Zagzebski, Linda (1996) Virtues of the Mind, Cambridge: Cambridge University Press.

[23] Zimmerman, Michael J. (2002). "Taking Luck Seriously," Journal of Philosophy, Vol. 99 (11):553-576. 